\title{
THE PLANS OF REFORM IN THE SPHERE OF SCIENCE AND TECHNOLOGY, AND THE CURRENT TASKS I.Dezhina
}

At present, several strategies addressing the sphere of science and technology are being elaborated. If one looks away from strategies and attempts to examine more thoroughly the actual practice and those issues that are being actively discussed by the specialists involved in that sphere, the existence of a significant gap between the issues that are the focus of attention of scientific research organizations, higher educational establishments, companies, and the scientific researcher community at large, as well as of the government departments responsible for the research and development sphere, on the one hand, and the priorities set by the strategies, on the other, will become obvious. Strategies appear to have little to do with the existing important problems. This does not mean, however, that no strategies are needed - on the contrary, in view of the absence of a systemic approach to providing solutions to these problems, it is especially important to introduce proper order into the existing situation and to select adequate instruments for and approaches to dealing with it. But it is the instruments to be applied that are the weakest point of the existing strategies. Besides, strategies must be geared to the real state of affairs, and not overlook the seemingly 'minor' issues capable of slowing down the development process.

Over the past six months, the relevant ministries, government departments and structures have begun to more actively address the task of developing new approaches and measures designed to improve the performance quality and productivity of scientific research, to speed up the development and practical implementation of new technologies, and to ultimately boost growth of the 'new economy'. Over that period, the Strategy for Scientific and Technological Development of the Russian Federation was being developed and perfected alongside the National Technology Initiative (NTI) Strategy until 2035. At present, the Center for Strategic Research (CSR) headed by Mr. Alexei Kudrin is starting to work on Russia's development strategy for 2018-2024 ${ }^{1}$, the sphere of science and technology being one of its aspects. It is expected that the new strategy will incorporate policies addressing the development of scientific research, technologies, and industry. So, the number of draft strategies prepared over recent months for the sphere of science and technology is higher than the number of those put forth over several past years.

Of course, such documents usually share some similar provisions, especially those that describe the existing situation, but every time the emphasis is placed differently. While the strategic documents focusing on the development of science and technology address specifically the scientific research field and the commercial use of intellectual products, the National Technology Initiative

1 Dmitry Medvedev and Alexei Kudrin discussed the work on the strategy for Russia's development from 2018 through 2024. Presidential Council for Economic Modernisation and Innovative Development. September 22, 2016. See http://i-russia.ru/all/news/31845/ 
Strategy also regards the sphere of science and technology as one of the important components of Russia's entry into new hi-tech markets, but assigns a major role in this entry to business activities. The existence of numerous new strategic documents (in addition to the already adopted ones, including several sectoral strategies, one of the most recent being, for example, the strategy for developing the field of photonics) is a sign of something like a crisis evolving in the sphere of science and technology, which is met with attempts to provide some sort of a solution. All this is taking place against the backdrop of reduced budget allocations to research and development (R\&D) projects, which also reduces the opportunities for implementing radical changes, because any measures in that directions are always costly. So, the set of instruments capable of producing positive effects should be selected with the utmost care.

The dwindling budget funding indeed poses a serious threat for the development of the scientific and technological complex, because the federal budget has always been and remains

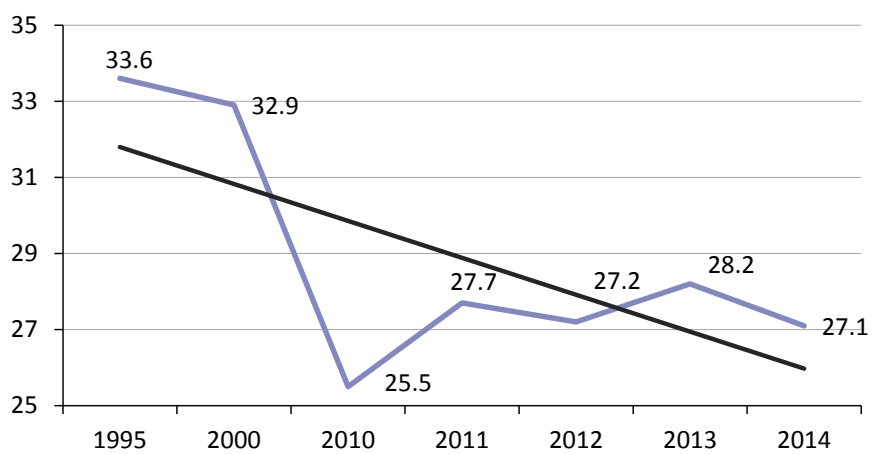

Source: Science Indicators: 2016. Statistics Collection. M.: NRU HSE, 2016, p. 72.

Fig. 1. Expenditures on R\&D in Russia's entrepreneurial sector, as \% of total national expenditures on $R \& D$

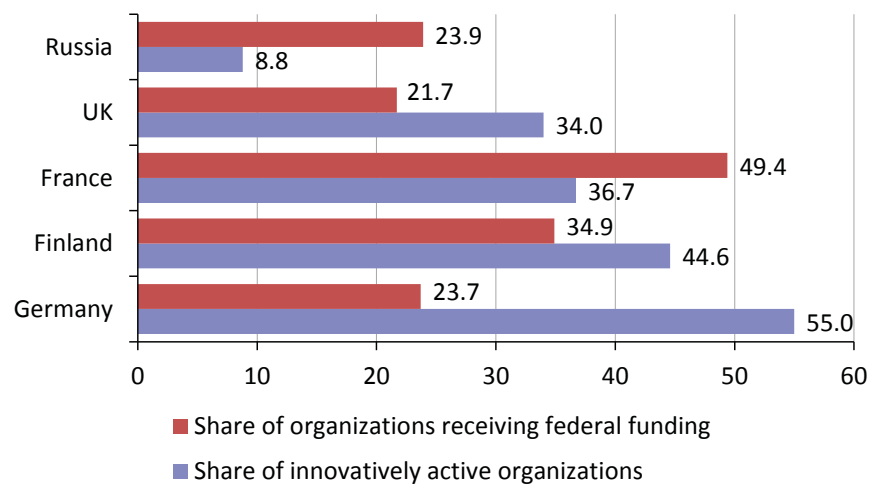

Source: Science Indicators: 2016. Statistics Collection. M.: NRU HSE, 2016, p. 301, 306.

Fig. 2. Organizations implementing technological innovations. Russia and the World: 2014 the main source of funding for R\&D projects, which can be allocated either directly through government programs and grants, or indirectly by allocating funding to innovative projects implemented in industry. In this connection, a typical indicator here is the share of the business sector in providing funding to R\&D, which is usually low, and is further declining (Fig. 1), and the relatively high level of budget subsidizing of the innovative activity in industry, which does not translate into any significant innovation growth (Fig. 2).

By way of example, the share of innovatively active organizations in Russia is less than $9 \%$ vs. $30-50 \%$ in the developed industrial countries; at the same time, nearly $24 \%$ of Russian companies receive federal funding allocated to technological innovations. In foreign countries (with the exception of France) the situation is exactly opposite: the share of innovatively active organizations exceeds that of the companies that are allotted federal funding specifically for that purpose (Fig. 2).

As stated in the latest Global Innovation Index 2016 Report $^{1}$ released in August, Russia, while having moved up 5 spots to the 43 rd place, still falls

1 The results of a comparative study of innovation systems in 128 countries. Source: The Global Innovation Index 2016. Winningwith global in novation. JOHNSON Cornell University, INSEAD, WIPO, 2016. https://www.globalinnovationindex.org/gii-2016-report 
significantly behind most countries in terms of some important parameters like innovation linkages (112th), rule of law (104th), state of cluster development (101st). This country still ranks high by its share of females employed with advanced degree ( 2 nd among a total of 128 countries), domestic market scale, and patent applications filed with the national patenting agency - but these are by no means the key innovation development parameters.

Thus, on the one hand, budget funding does play a major role in Russia's sphere of science and technology, while on the other, as demonstrated by actual practice, its availability - and even growth - is not a key success factor. Evidently, some non-financial mechanisms, both inside and outside of the sphere of science and technology, are needed in order to boost performance and the quality of newly created technologies.

Each of the current strategies relies on its own core idea. For the NTI Strategy, it is the entry into new network markets by means of developing structured (backup) technologies, and setting up 'NTI companies'. The Strategy for Scientific and Technological Development of the Russian Federation is oriented to 'big challenges' that can serve as stimuli for promoting science and technologies. In this connection, 'big challenges' are understood as 'a set of problems, risks and opportunities, relevant factors and long-run processes' ${ }^{2}$. The examples of 'big challenges' are the anthropogenic burden on the environment with its socioeconomic risks and even threats to human health and life; demographic changes; social segregation; deteriorating performance and manageability of key infrastructure systems (finance, transport, energy), etc. As follows from this list of risks, many countries will face similar 'big challenges'. The orientation to 'big challenges', according to the strategy ideologists, implies a change in the governance paradigm - from the management of organizations to the management of priorities. However, it is not quite clear how this can be realized in actual practice, because it is very difficult to operate a major category like 'a big challenge', unless it is reduced to the launch of yet another bunch of 'priority programs'. Another noteworthy feature is that the strategy's orientation to network markets is not compatible with that to 'big challenges'. Indeed, promising markets must not necessarily be found where challenges are also present - instead, they may spring up somewhere in connection with suddenly emerging breakthrough hi-tech inventions (as one example).

Another problem typically associated with the currently suggested draft strategies is their high degree of generalization and lack of properly elaborated specific plans. The main emphasis is placed on the general principles, while the mechanisms of their implementation play a subordinate role, and are not always understandable. More vagueness is created by the uncertainty as to the specific areas of responsibility assigned to each of the ministries, government departments and other organizations selected for the strategy's implementation. And finally, the expected results are poorly coordinated

1 A 'NTI company' builds its business on breakthrough technological solutions and technologies that allow the achievement of much higher results at a lower cost.

2 St. Petersburg International Economic Forum (SPIEF). June 16, 2016. Panel session. The Big Challenges in Promoting Scientific Development. https://www.google.ru/url?sa=t\&rct=j\& $q=\& e s r c=s \&$ source $=$ web\& $c d=4 \& v e d=0$ ahUKEwjUjKPWkK_PAhXGDSwKHbmtCoEQFggsMAM\& url=http\%3A\%2F\%2Fyoungscience.gov.ru\%2Fmedia\%2Ffiles\%2Ffile\%2FkMS9X6hbigAyTDwb ALxFWfMGNABr7OYM.pdf\&usg=AFQjCNF9JaJkPWWDJFz7yr4URYcIMhiZrw\&sig2=9LluSxOFeF FAcecUQS7K1A\&bvm=bv.133700528,d.bGg\&cad=rjt 
with the declared goals (for example, the solutions to the issues described as 'big challenges').

If we look away from the strategies and towards those issues that are being actively discussed in the sphere of science and technology, we will see the existence of a significant gap between the issues that are considered to be important by scientific research organizations, higher educational establishments, businesses, the academic community, and the government departments responsible for the implementation of research and development projects, on the one hand, and the priorities set in the strategies, on the other.

The ongoing discussion of the issues relating to scientific research (and in part to technological development policy) has once again entered a crisis mode, in that its main themes are the possible consequences of the cuts on budget funding; the potential scale of personnel cuts; the real cost-effectiveness of the resource-intensive 'showcase' programs like the government mega-grants ${ }^{1}$; the dangers associated with a merger of scientific research organizations and higher educational establishments. Another ongoing discussion centers on research ratings and citation indices. In particular, it is questioned which indices should be applied, and how the goal of upgrading Russia's WEB of Knowledge index set in the President of the Russian Federation's Executive Order can best be achieved ${ }^{2}$. It should be noted in this connection that this theme is also being hotly discussed at the international level, and new ranking indices are being suggested that can more accurately reflect the contribution of scientific journals and individual researchers in the development of science ${ }^{3}$. In fact, this is the manifestation of the strengthening trend towards using citation indices as a measure of success achieved by individual authors, as well as by research laboratories and institutes, to be used as a foundation for decision-making when allocating funds and human resources.

The issue of performance assessment indices is closely associated with that of personnel qualification. One of the hotly debated issues in this sphere is the potential role of the Russian academic diaspora abroad. Is it really worthwhile to attract the Russian expat scientists back into their native country, or perhaps it would be better to cooperate with them in one or other form? Not long ago, the figure ' 15,000 ' emerged (as the number of Russian expat researchers to be enticed to return) ${ }^{4}$. As is typical of any discussion of the expat theme, such figures are rarely based on precise calculations or any large-scale quantitative studies. In this connection, as the Russian dias-

1 Mega-grants are big monetary grants (initially in the amount of $\mathrm{Rb} 150 \mathrm{~m}$ for three years, later up to $\mathrm{Rb} 90 \mathrm{~m}$ for three years) allocated with the purpose of establishing world-class laboratories in existing Russian universities and research centers. The project was launched after the issuance of RF Government Decree No 220 'On Measures Designed to Attract Leading Scientists to Russian Educational Establishments for Higher Professional Learning' (of April 10, 2010).

2 Executive Order of the President of the Russian Federation of May 7, 2012, No 599 'On Measures to Implement Government Policy on Education and Science', where it is stipulated that, by 2015, Russia's WEB of Knowledge index should be increased to $2.44 \%$. See https:// rg.ru/2012/05/09/nauka-dok.html

3 See, e.g., Bjorn Hammarfelt, Alexander Rushforth (2016). Judging merits in the age of the h-index: Citizen bibliometrics in biomedicine and economics. https://arxiv.org/ pdf/1609.04931; Loet Leydesdorff, Paul Wounters, and Lutz Bornmann (2016). Professional and Citizen Bibliometrics: Complementarities and ambivalences in the development and use of indicators. https://arxiv.org/pdf/1609.04793v1.pdf

4 See, e.g., Russia decides to get back 15,000 scientists from abroad. http://www.silver.ru/ news/130303/ 
pora is getting increasingly involved in domestic research projects (and this is indeed happening thanks to the program designed to ensure that five Russian universities should be placed on the world's Top 100 list), the number of both champions to and opponents of the cooperation has been on the rise. However, on the whole, everybody agrees that cooperation should be promoted on an international scale, and not only in the framework of the Russian expat community.

Thus, some solutions are being provided to the hottest issues, and it often happens sporadically - sometimes by way of resisting to the initiatives put forth by government departments (the irrational merger of research organizations, changes in the form of ownership or the principles of funding allocation, salary payment, and personnel qualification assessment). In the presence of the numerous disputable and as yet unsolved problems, including purely technical ones, relating to all the aspects of the sphere of science and technology (human resources, funding, organizational structure, management systems, material base and material backing for the research processes), 'big challenges' and 'potential markets for 2035' appear to be purely theoretical concepts, and so the strategies fail to address the real everyday issues. This does not mean, however, that no strategies are needed. On the contrary, in view of the current non-systemic approaches to those issues, it is especially important that proper order should be introduced into the existing situation, and proper instruments and approaches selected. But it is precisely the instruments that are not properly defined in the existing strategies. And besides, the strategies must be geared to the real state of affairs and not overlook the seemingly 'minor' issues capable of slowing down the development process.

The major aspects that should be reflected in the strategies are the need to rethink the areas of responsibility assigned to federal and regional authorities in the fields of education, science and innovation, to precisely define the principles of international cooperation and interaction, and to draw up a list of economic measures (relating to taxes, customs, budgeting, organizational issues) designed to boost the demand for technological innovations. 